\title{
A CONSTRUÇÃO TRANSITIVA EM PB: ASSOCIANDO A GRAMÁTICA DE CONSTRUÇÕES À DECOMPOSIÇÃO LEXICAL
}

\author{
Larissa CIRÍACO*
}

- RESUMO: Este artigo propõe mostrar como a teoria gramatical de construções (GOLDBERG, 1995, 2006) pode ser associada a uma metodologia semântico-lexical de análise de classes de verbos, a saber, a decomposição dos sentidos dos verbos em predicados semânticos primitivos. Em outras palavras, mostramos, principalmente, como a decomposição semântica de predicados pode ser uma ferramenta útil na descrição do significado de construções de estrutura argumental. Para exemplificar a proposta, fazemos uma análise da construção transitiva em português. Seis grandes classes de verbos do português brasileiro também são analisadas em suas respectivas elaborações da construção transitiva, tendo suas representações semânticas apresentadas. O objetivo é chegar ao significado da construção, que, como mostramos, não pode ser descrito em termos gerais, ou seja, não pode ser dado em função de um único significado esquemático, mas sim em função de uma rede de significados relacionados, que podem ser entendidos como extensões metafóricas a partir de um significado prototípico. Para completar a análise fornecemos uma representação da construção transitiva em seu significado prototípico.

- PALAVRAS-CHAVE: Construção transitiva. Gramática de construções. Decomposição lexical. Classes de verbos.

\section{Introdução}

Este artigo apresenta uma proposta de vinculação da teoria da Gramática de Construções (especialmente, Goldberg $(1995,2006))$ com uma metodologia de análise semântico-lexical, a saber, a decomposição do sentido dos verbos em predicados semânticos primitivos. Essa proposta se destina à análise de construções de estrutura argumental, uma subclasse especial de construções das línguas, segundo Goldberg (1995). Vamos propor que o significado das construções de estrutura argumental pode ser representado a partir das descrições em predicados semânticos primitivos das classes de verbos que elaboram esses padrões oracionais.

Para ilustrar a proposta, vamos tomar a construção transitiva, uma construção de ocorrência mais ampla nas línguas do mundo, e algumas classes de verbos

* UFLA - Universidade Federal de Lavras. Departamento de Ciências Humanas. Lavras - MG - Brasil. 37200 000 - larissaciriaco@ufla.dch.br 
do português. A metodologia de análise aqui proposta pode ser usada na caracterização de outras construções, como mostram, por exemplo, as análises de Ciríaco (2011) e Ciríaco (2012). A análise da construção transitiva será feita com base em seis grandes classes de verbos do português brasileiro (doravante PB), conforme Ciríaco (2011), e suas respectivas representações semânticas, a saber: verbos estritamente agentivos, verbos causativos/agentivos, verbos estritamente causativos, verbos de obtenção, verbos de experiência e verbos de estado. As representações semânticas das classes de verbos analisadas são baseadas em trabalhos como Ciríaco (2011), Levin (1993), Levin e Rappaport-Hovav (1995, 1998, 2010) e Cançado (2010). Adotando essa metodologia, será possível descrever alguns dos significados associados à construção transitiva em PB.

A análise que decorre da proposta ainda corrobora a ideia de Goldberg de que a construção transitiva pode ser mais bem descrita a partir de uma rede de sentidos relacionados, e não apenas a partir de um único sentido mais geral, pois não há um sentido mais geral que possa capturar todas as instâncias da construção transitiva. Adotamos, portanto, a ideia de haver um significado mais prototípico e outros a ele relacionados. Por fim, realçamos que a pesquisa não tem o propósito de ser exaustiva, mas refere-se a algumas classes de verbos do português, que, embora não alcancem a sua totalidade, são bem representativas na língua.

\section{A gramática de construções e a decomposição semântica de predicados}

Em Gramática de Construções, a noção de construção é fundamental. Uma construção é uma unidade linguística, dotada não apenas de forma ou sentido, mas de ambos, à semelhança da noção de signo linguístico postulada por Saussure. Descrever as construções linguísticas significa, então, descrever seu polo sintático e seu polo semântico. Essa abordagem também considera que as construções sejam as únicas unidades da gramática, variando apenas em complexidade e esquematicidade ao longo de um contínuo de construções, que vai do léxico mais específico e de menor complexidade - à gramática - mais esquemática e de maior complexidade. Por exemplo, em poucas palavras, "livro" é uma construção menos complexa e menos esquemática do que o padrão oracional SVO. Nesse contexto, Goldberg (1995) explora, em sua Gramática de Construções, uma subclasse especial de construções linguísticas, as construções de estrutura argumental. Essas construções são padrões oracionais, e, portanto, de tipo mais esquemático. A grande vantagem de se reconhecer padrões oracionais como construções está em se reconhecer um significado próprio a eles, independente dos itens lexicais que os preenchem, e, mais especificamente, independente do significado de verbos. Por exemplo, a construção transitiva é, segundo Goldberg, uma construção de estrutura argumental, cuja forma sintática é SVO 
(em português, inglês e em várias outras línguas) e cujo significado prototípico envolve uma transferência entre um agente e um paciente. ${ }^{1}$

A integração entre verbos e construções de estrutura argumental é governada por dois princípios, segundo Goldberg: o Princípio da Coerência Semântica, de acordo com o qual apenas papéis semanticamente compatíveis podem fundir-se, e o Princípio da Correspondência, segundo o qual cada papel participante do verbo deve ser expresso e fundido com um papel argumental da construção. Assim, um verbo pode elaborar uma construção de estrutura argumental quando houver compatibilidade semântica entre ele e a construção. E essa compatibilidade semântica implica compatibilidade entre os papéis argumentais da construção, que são "lugares" (slots) na representação semântica das construções, e os papéis participantes do verbo, que são "lugares" na representação semântica dos verbos (GOLDBERG, 1995, p.110). A distinção entre papéis participantes e argumentais serve para capturar o fato de que verbos estão associados a uma semântica rica e bem específica e, portanto, a papéis semânticos também específicos. Por exemplo, o verbo "quebrar" está associado aos papéis participantes "quebrador" e "quebrado". Já o sentido de uma construção de estrutura argumental corresponde a "estruturas semânticas decomposicionais" (GOLDBERG, 1995, p.28), ou seja, a esquemas de eventos, como "X causa $Y$ receber Z" ou "X age", etc., e a papéis mais esquemáticos, como "agente", "paciente", etc.

Seguindo essa ideia, as representações do significado das classes de verbos em predicados semânticos primitivos podem ser usadas na descrição e/ou representação do significado da construção de estrutura argumental estudada, podendo tanto equivaler ao significado da construção quanto funcionar como um passo na determinação desse significado. Para representar os significados dos verbos, vamos adotar a técnica de decomposição de seu sentido tal qual desenvolvida nos trabalhos de Levin e Rappaport-Hovav (1995, 1998, 2010). É essa articulação que pretendemos explorar um pouco mais neste trabalho. Vejamos mais detalhadamente como isso se daria.

A decomposição do significado em predicados primitivos é uma análise do sentido dos verbos com o intuito de fornecer uma representação semântica do evento denotado por eles e agrupá-los conforme os tipos de eventos que nomeiam. Essa representação é alcançada por meio da decomposição do significado dos verbos em elementos semânticos básicos, os predicados semânticos primitivos, que representam os componentes de significado que são recorrentes nos grupos de verbos (LEVIN; RAPPAPORT-HOVAV, 2005). Essa ideia tem sido explorada por muitos semanticistas lexicais (JACKENDOFF, 1990; LEVIN; RAPPAPORT-

Goldberg não chega a definir uma representação para a construção transitiva, mas sugere um significado prototípico e retoma considerações sobre o assunto feitas por outros autores (KEMMER, 1993; LANGACKER, 1987, 2008; GIVÓN, 1984). Partiremos dessas ideias para construir nossa análise. 
HOVAV, 1995, 1999, 2005, 2010; VAN VALIN; LAPOLLA, 1997; VAN VALIN, 2005; WUNDERLICH, 1997, 2000, 2009; etc.) e pode ser entendida como uma teoria de tipos de eventos. As decomposições permitem não apenas verificar os aspectos de significado mais gerais associados a uma classe de verbos, mas também preservam os aspectos mais específicos e idiossincráticos de seu significado, que são atribuídos à "raiz". Por exemplo, no trabalho de Cançado (2010), é proposta a seguinte representação para os verbos causativos/agentivos do português, com base em Levin e Rappaport-Hovav (2005, 2010):

\section{(1) $\quad$ v. [[X (ACT)] CAUSE [Y BECOME <RESULT-STATE $>]]^{2}$}

Nessa representação, ACT, CAUSE e BECOME são predicados ${ }^{3}$ semânticos primitivos e $\mathrm{X}$ e $\mathrm{Y}$ correspondem aos participantes associados ao verbo. $\mathrm{O}$ predicado ACT se encontra entre parênteses para marcar sua opcionalidade, indicando que o verbo pode ser agentivo ou causativo. ${ }^{4} \mathrm{O}$ elemento entre colchetes angulados é a "constante" (LEVIN; RAPPAPORT-HOVAV, 1998) ou "raiz" (LEVIN; RAPPAPORT-HOVAV, 2005), que representa o sentido idiossincrático de cada verbo. ${ }^{5}$ Para um verbo dessa classe, como "quebrar", a representação específica seria:

(2) quebrar. [[X (ACT)] CAUSE [Y BECOME < QUEBRADO>]]

A partir das representações semânticas, é possível inferir os papéis participantes dos verbos, de acordo com a posição que eles ocupam em relação aos predicados. Por exemplo, no caso da representação semântica de "quebrar", o participante X pode estar associado ao papel de agente, caso em que ACT está presente ("João quebrou a janela com uma tacada"), ou ao papel de causa, no caso de ACT não estar presente ("O vento quebrou a janela"). O participante Y, sendo argumento de BECOME, que denota uma mudança, está associado ao papel prototípico de paciente. A raiz, de tipo ontológico STATE, remete a um estado resultante, capturada por um adjetivo relacionado, que, no caso de "quebrar", é o adjetivo "quebrado". Sendo responsável pela parte idiossincrática do significado,

\footnotetext{
Optamos por manter os predicados primitivos em inglês, como já estabelecido na literatura em semântica lexical.

3 Os predicados semânticos primitivos mais utilizados em estudos usando estruturas léxico-conceptuais ou outras formas de decomposição são ACT ou DO, BE, BECOME ou CHANGE, CAUSE, GO, etc. Outros predicados, como HAVE, MOVE, STAY, RESULT, também aparecem. Jackendoff (1990) também postula outros predicados ainda.

4 Cançado representa a opcionalidade de ACT partindo de ideia de Jackendoff (1990, cap.4).

5 Levin e Rappaport-Hovav (1998) propõem que as raízes são de diferentes tipos ontológicos. Dois tipos de raízes principais são "manner" e "result" (LEVIN; RAPPAPORT-HOVAV, 1991, 1995, 2010; TALMY, 1976, 2000; FOLEY; VAN VALIN, 1984; VAN VALIN; LAPOLLA, 1997).
} 
a raiz permite incorporar a observação de Goldberg (1995) de que os verbos estão associados a uma semântica ainda mais rica do que aquela capturada apenas por predicados semânticos primitivos.

Essas representações semânticas funcionam, neste trabalho, como esquemas semânticos para agrupamentos de verbos. Por exemplo, a representação semântica dada em (1) funciona como um esquema para a classe de verbos causativos/agentivos, indicando os componentes de sentido que eles têm em comum, por meio dos predicados, e os aspectos de significado que lhes são específicos, por meio da raiz. Portanto, essas representações semânticas também podem ser entendidas como construções, pois o significado que representam está associado à classe morfossintática esquemática $V$ (verbo). A diferença entre a representação semântica de uma classe verbal e um verbo específico está apenas no nível de esquematicidade: enquanto a representação é uma unidade esquemática, de significado mais geral, o verbo é uma unidade de conteúdo, mais específica (LANGACKER, 2008). Em realidade, a proposta de Levin é também uma proposta construcional, pois procura explicitar um significado para estruturas argumentais. E, como as representações semânticas emergem dos significados individuais dos verbos que as compõem, assim como toda construção esquemática, faz sentido, portanto, examinar detidamente o significado das classes de verbos compatíveis com a construção estudada a fim de determinar o significado dessa construção.

Assim, para determinar o significado de uma construção da língua, procedemos da seguinte maneira: primeiramente, faz-se uma checagem da compatibilidade de cada classe de verbos com a construção estudada, que, no caso deste artigo, é a construção transitiva (o agrupamento dos verbos analisados em classes pode sofrer alterações, de acordo com o que for mais pertinente/relevante para a construção em estudo). Posteriormente, procede-se à verificação das descrições semânticas das classes de verbos compatíveis com a construção estudada. Essa análise é importante para a descrição do significado da construção. Nesse passo, é importante verificar: os predicados semânticos mais recorrentes, a possibilidade de se generalizar quanto a um aspecto de sentido comum entre as classes ou a possibilidade de estabelecer uma rede de sentidos relacionados para a construção estudada, baseando-se num significado mais prototípico (talvez, mais frequente) e em significados menos prototípicos, mas que se relacionam. Algumas situações possíveis são: quando a construção se compatibiliza com apenas uma classe ou grupo de verbos, então seu significado é igual ao significado dessa classe ou à parte do significado dessa classe e pode ser representado usando-se a própria representação proposta para a classe. Já quando a construção se compatibiliza com mais de uma classe de verbos, é preciso investigar se essas classes podem ser analisadas como que formando um grupo semântico maior e mais geral ou se essas classes devem ser tratadas como extensões metafóricas de um significado 
prototípico. No primeiro caso, o significado da construção pode ser descrito em termos do significado do grupo formado pelas classes compatíveis; já no segundo caso, o significado da construção será descrito em termos de uma rede de significados relacionados, sendo o significado de uma classe tomado como prototípico e os significados das outras como relacionados a esse significado principal.

Para finalizar esta parte do artigo, é importante lembrar que as construções de estrutura argumental, associando uma forma a um significado, apresentam as funções de: mostrar de que modo os verbos combinam-se com elas, restringir a classe de verbos que podem integrar-se a elas e também especificar o modo como o tipo de evento designado pelo verbo integra-se ao tipo de evento designado por elas. Portanto, descrever um significado construcional significa descrever as condições de elaboração dessa construção em uma língua. Além disso, o mapeamento entre semântica e sintaxe, numa abordagem construcional, não requer mecanismos extras. Tudo é feito por meio de uma única unidade gramatical, ou seja, a construção, dispensando a necessidade de se postular regras de projeção ou outros mecanismos lexicais.

\section{Classes de verbos do português e a construção transitiva}

Antes de determinarmos o significado da construção transitiva, vamos analisar o significado de algumas classes de verbos que a elaboram. A construção transitiva possui ocorrência ampla entre os verbos da língua, sendo frequentemente considerada o padrão de expressão oracional mais básico nas línguas de orientação agentiva (LANGACKER, 2008). Entretanto, neste artigo, vamos nos ater a apenas seis grandes classes de verbos, que consideramos mais representativas, para descrevê-la: os verbos de estado, os verbos de experiência, os verbos de obtenção, os verbos estritamente causativos, os verbos causativos/agentivos e os verbos estritamente agentivos. Os verbos analisados constituem um recorte do corpus coletado e analisado por Ciríaco (2011) e decorrem da análise de 138 dos mais de 150 verbos coletados e analisados pela autora e suas respectivas elaborações da construção transitiva. ${ }^{6}$

A classe dos verbos de estado compreende verbos que lexicalizam uma relação entre um participante X e um participante Y, como: "custar", "medir", "possuir", "ter", etc. A representação semântica usada para essa classe foi v: [X $<$ RELATION> Y] (CIRÍACO, 2011). Dentro dessa classe, há verbos que podem estar associados a mais de uma conceptualização, como é o caso do verbo "medir".

\footnotetext{
A análise de Ciríaco (2011) compreende mais de 450 sentenças. A coleta dos verbos baseou-se, principalmente, em dicionários e em outros corpora de teses e dissertações da UFMG. Para maiores informações, consulte-se o trabalho da autora.
} 
Esse verbo pode estar associado a uma conceptualização estativa, como em "essa sala mede dois metros quadrados", ou a uma conceptualização agentiva ou causativa, como no caso de "ele mediu a sala". No primeiro caso, a representação semântica associada a "medir" é a de um estado puro. Já no segundo caso, tratase de uma conceptualização agentiva, para a qual a representação seria outra. Estamos tratando, portanto, ao delimitar essa classe de verbos de estado, apenas de conceptualizações estativas das descrições de eventos, reservando outras conceptualizações a outras classes. A compatibilização dos verbos de estado com a construção transitiva ocorre naturalmente, como mostram os exemplos que se seguem:

(3) Essa bolsa custa 500 reais.

(4) Essa sala mede dois metros quadrados.

(5) Paulo possui uma coleção de carros antigos.

A segunda classe é a dos verbos de experiência, como "amar", etc. Esses verbos lexicalizam a conceptualização de um evento de experiência psicológica direcionado de um participante X para um participante Y. Por exemplo, o verbo "amar" denota uma experiência de amor de X para Y. A representação usada para essa classe é $v$. [X EXPERIENCE <THING $>$ for Y] (CIRÍACO, 2011). O aspecto de sentido comum a todos os verbos dessa classe, que é a experiência, é representado pelo predicado EXPERIENCE. A raiz, de tipo ontológico THING, especifica o tipo de experiência lexicalizada por cada verbo em particular. Por exemplo, no caso de "amar", X experiencia amor por Y. Exemplos desses verbos na construção transitiva são:

(6) Fernanda ama Estêvão.

(7) Eu adoro doces e sobremesas.

(8) Esses alunos respeitam seus professores.

Outra classe analisada foi a dos verbos de obtenção, como "ganhar", "conseguir", "obter", etc., que estão, segundo Levin (1993), associados a uma cena em que o participante X obtém, de certa maneira, o participante Y. Para representar o significado dessa classe, Ciríaco (2011) propõe o predicado primitivo GET, que representa o aspecto de sentido comum a esse grupo de verbos, que é a obtenção. A representação ainda contém uma raiz que especifica o modo de obtenção, ou seja, MANEIRA, sendo descrita como v: [X GET Y]. Uma peculiaridade dessa classe de verbos é que alguns deles atribuem, necessariamente, propriedades como esforço ou intenção ao participante associado a X, enquanto outros podem ou não atribuí-las, dependendo da 
composição semântica dos elementos na sentença. Por exemplo, em "X conseguiu $Y$ ", $X$ teve, necessariamente, a intenção ou o interesse em conseguir Y. Já no caso de verbos como "ganhar", esse aspecto de sentido pode emergir ou não: em "X ganha um presente", não se pode inferir que X, necessariamente, se esforçou ou teve interesse em ganhar o presente. Já em "X ganhou uma aposta", a composição dos significados de "ganhar" com "uma aposta" permite inferir que X teve, necessariamente, a intenção de ganhar a aposta. Essa peculiaridade é interessante do ponto de vista descritivo, mas não faz diferença na compatibilização dessa classe de verbos com a construção transitiva:

(9) Paulo conseguiu um emprego.

(10) O amigo da Joana ganhou a aposta/várias garrafas de vinho no seu aniversário.

(11) O atlético venceu o campeonato.

Os verbos estritamente causativos são verbos como "preocupar", etc., que envolvem um participante X que só pode ser conceptualizado como causa, nunca como agente (CIRÍACO; CANÇADO, 2009). Para esses verbos, o participante X sempre denota um evento, e por isso não pode ser entendido como um agente, pois um agente implica as propriedades de volição, iniciativa, controle, etc., própria de seres animados. Por seu turno, o participante Y está sempre relacionado a uma mudança de estado psicológica. Um exemplo de verbo dessa classe é o verbo "preocupar", como em "João preocupa Maria". Nessa sentença, "João" não pode ser interpretado como um agente, mas apenas como causa, pois sabemos que não é o João em si que preocupa Maria, mas algo que ele faz ou alguma característica que ele possui. Para esses verbos, a representação usada será [[X] CAUSE [Y BECOME <STATE>]], tal como propõe Cançado (2010), baseada em Parsons (1990). Nessa representação, o participante X não está associado a nenhum outro predicado semântico primitivo além de CAUSE, mostrando que seu papel só pode ser o de causa, nunca o de agente. A parte da representação que inclui o participante $Y$ denota uma mudança de estado, e é consenso entre os semanticistas lexicais para representar esse aspecto de sentido. Exemplos de verbos estritamente causativos na construção transitiva são:

(12) João preocupou Maria.

(13) A mãe aborreceu a filha.

(14) Essa peça me encantou.

Os verbos causativos/agentivos, como "quebrar", etc., por sua vez, não envolvem um participante $\mathrm{X}$ necessariamente agentivo, ou seja, dotado de volição, iniciativa, controle, etc., mas também não requerem um participante que 
só pode ser interpretado como causa. Esses verbos envolvem um participante $\mathrm{X}$ que pode ser conceptualizado ora como um agente prototípico, ora como uma causa (CIRÍACO; CANÇADO, 2009). Por exemplo, no caso dos verbos causativos/agentivos, o desencadeador do evento descrito por "quebrar", ou seja, o participante X, pode ser conceptualizado como agente, no caso de a sentença ser algo como "Lia quebrou a janela com uma marreta", ou como causa, no caso de a sentença ser algo como "Lia quebrou a janela (sem querer)". Para capturar a possibilidade de conceptualização de $\mathrm{X}$ ora como agente, ora como causa, a representação usada para essa classe de verbos inclui o predicado primitivo ACT entre parênteses, indicando sua opcionalidade, ou seja, v. [[X (ACT)] CAUSE [Y BECOME <STATE ]] (CANÇADO, 2010). Exemplos de verbos dessa classe na construção transitiva são:

(15) Os meninos quebraram a janela.

(16) Cida abriu a porta para mim.

(17) Eduardo esvaziou o filtro.

Por fim, vamos analisar os verbos estritamente agentivos. Essa classe é numerosa em português, assim como em muitas outras línguas de orientação agentiva e deve ser, provavelmente, a classe mais frequentemente associada à construção transitiva. Os verbos dessa classe são verbos como "limpar", "lavar", "cortar", "ajudar", "construir", etc., e estão associados, necessariamente, a um participante agentivo prototípico, ou seja, dotado de volição, intencionalidade ou controle. Essa classe de verbos é, na verdade, um grande grupo de verbos, que pode ser subdividido dependendo do efeito que o participante agentivo X tem sobre o participante Y. Há, portanto, assimetria semântica entre os participantes do evento denotado por um verbo dessa classe: enquanto $\mathrm{X}$ age e provoca um efeito, $Y$ recebe essa ação e sofre seu efeito. $O$ efeito produzido em $Y$ pode ser de vários subtipos, mas, para os fins deste trabalho, não iremos subdividi-lo. Vamos tratar o efeito produzido em Y como uma afetação, em termos bem gerais, seja ela uma limpeza, um corte, uma ajuda, uma construção de algo, etc. Essa afetação geral será descrita pelo uso da raiz "affectedness": [[X ACT] CAUSE [<AFFECTEDNESSS of Y]], conforme proposto em Cançado (2010). Exemplos de construções com verbos dessa classe são:

(18) Maria cortou o bolo.

(19) O secretário arquivou os documentos.

(20) A construtora construiu novos prédios.

(21) Os fiéis ajudam a erguer a igreja. 
Tendo analisado semanticamente todas essas classes, nos perguntamos o que elas têm em comum, em termos semânticos, que nos permita identificar um significado para a construção transitiva. Afinal, é desejável que o significado de uma construção seja o mais geral possível. Mas, se procurarmos por propriedades de sentido nas representações semântico-lexicais de cada classe, será difícil achar uma característica generalizante. Nem a assimetria semântica entre os participantes é uma característica comum entre as classes. Vejamos o que é essa noção e como ela se manifesta nas classes analisadas. Primeiramente, é preciso notar que todos os verbos analisados evocam dois participantes em seu esquema de evento. Cada participante ocupa uma posição na estrutura sintática da construção transitiva - sujeito ou objeto. Como é sabido, a posição de sujeito é uma posição proeminente, que reflete, muitas vezes, uma hierarquia de funções ou alguma saliência discursiva e/ou cognitiva do participante que a ocupa (GOLDBERG, 1995). Assim, a atribuição de um participante à posição de sujeito e de outro à posição de objeto depende da proeminência de cada participante. Um participante com características agentivas, por exemplo, tem a preferência para ocupar a posição de sujeito. Essa atribuição reflete, portanto, uma assimetria semântica entre os participantes.

Prototipicamente, dois participantes são assimétricos quando um é agente e o outro é paciente. Um evento desse tipo, como aquele descrito pelo verbo "limpar", se encaixa prototipicamente no modelo cognitivo da cadeia causal (CROFT, 1991, 1998; CROFT; CRUSE, 2004; LANGACKER, 1987; TALMY, 1976, entre outros), pois envolve causação volitiva de um agente para um paciente. Assim, para verbos agentivos, a assimetria entre o participante $\mathrm{X}$ e o participante $\mathrm{Y}$ está no fato de que $\mathrm{X}$ transfere/direciona energia para $\mathrm{Y}$, pois enquanto $\mathrm{X}$ age e provoca um efeito, Y recebe essa ação e sofre seu efeito. Da mesma maneira, há assimetria entre os participantes de eventos causativos/agentivos, como o descrito pelo verbo "quebrar": X transfere uma ação/causação paraY, que a recebe e sofre seus efeitos. Podemos estender a mesma ideia para verbos estritamente causativos. Por exemplo, em "João preocupa Maria", João é aquele que direciona a preocupação para Maria. Essa mesma noção, de transferência ou direcionamento, também parece funcionar para verbos de experiência, no sentido em que a experiência descrita pelo verbo é "direcionada" de um participante para outro e, portanto, há aquele que direciona a experiência e aquele que a recebe ou é alvo dela. Por exemplo, o verbo "amar" denota uma experiência de amor de X para Y. Como o participante que direciona a experiência está associado à posição de sujeito na construção transitiva, ${ }^{7}$ podemos considerar que essa noção de direção da experiência manifesta a assimetria semântica entre os participantes evocados por esses verbos.

Esse aspecto de sentido também parece ter um papel na compatibilização dessa classe de verbos com a construção passiva (CIRÍACO, 2011). 
Entretanto, a assimetria semântica não parece funcionar tão bem para verbos de obtenção: o participante X é aquele que obtém e Y é aquele que é obtido. E o mesmo acontece para os verbos de estado, para os quais não existe assimetria entre os participantes. Por exemplo, o verbo "custar" lexicaliza uma relação de custo entre um objeto e um valor. Essa é apenas uma relação entre um participante e outro, e não algo que acontece ou se desenvolve entre eles. Daí ser considerada um estado e não um evento. Qualquer um dos participantes poderia, em princípio, ocupar a posição de sujeito ou de objeto, por exemplo. Entretanto, sabemos, para o verbo "custar", que é o participante "objeto" que ocupa a posição de sujeito e é o participante "valor" que ocupa a posição de objeto. Essas noções, entretanto, não são sistemáticas nessa classe. Por exemplo, para o verbo "ter", é o "possuidor" que ocupa a posição de sujeito e o "possuído" que ocupa a posição de objeto. Já para o verbo "medir", um "objeto" ocupa a posição de sujeito e uma "medida" ocupa a posição de objeto. Portanto, a assimetria sintática entre os participantes dessas classes de verbos não é motivada semanticamente, mas parece ser algo a que esses verbos são coagidos a se encaixarem, a fim de se adequarem ao padrão de expressão oracional prototípico da língua - a construção transitiva (CROFT, 1991).

Essa noção geral de assimetria semântica entre os participantes parece ser um aspecto importante da semântica da construção transitiva, entretanto ela ainda não parece adequada para descrever o significado da construção. Em realidade, ela parece ser importante, neste trabalho, para identificar o significado prototípico da construção transitiva, que é aquele que mais bem reflete a noção de assimetria analisada anteriormente. Ou seja, vamos tomar o sentido veiculado por verbos agentivos e causativos como o significado prototípico da construção, por esse ser o sentido que mais tipicamente reflete a assimetria semântica característica de um evento típico no modelo cognitivo de cadeia causal. Mas esse não é o único significado associado a ela. Outros significados existem, estando relacionados ao significado prototípico por uma relação de extensão metafórica - do mais concreto ou físico para o mais abstrato ou metafísico. A próxima seção vai mostrar como a relação entre esses significados pode ser representada.

\section{Representando a construção transitiva no PB}

Como não parece haver um significado mais geral para a construção transitiva, vamos assumir, em conformidade com a hipótese de Goldberg (1995), que o significado da construção transitiva pode ser mais bem descrito em termos de uma rede de significados relacionados. Para definir esses significados, usaremos as descrições semânticas das classes analisadas na seção anterior. O diagrama seguinte expressa essa rede de significados que caracteriza a construção transitiva: 
Figura 1 - Diagrama de significados da construção transitiva

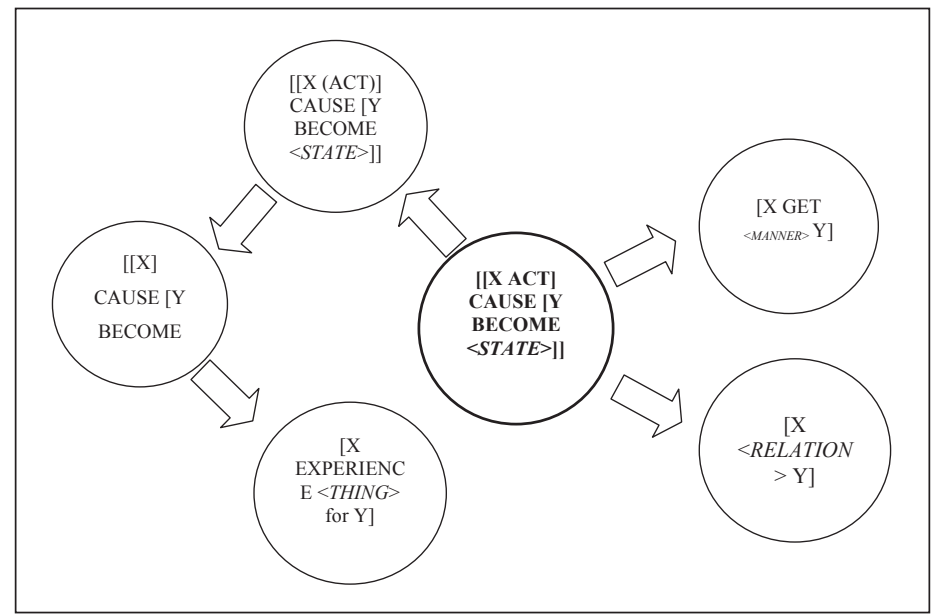

Fonte: Elaboração própria.

No diagrama, o significado prototípico da construção transitiva está marcado em negrito. Esse é o significado central, a partir do qual os outros significados se organizam. Os demais significados, [[X (ACT)] CAUSE [Y BECOME <STATE $>$ ]], [[X] CAUSE [Y BECOME <STATE $>$ ]] e [X EXPERIENCE <THING> for Y], se relacionam ao significado central como extensões metafóricas. Há, portanto, como sentido central, uma transferência de ação de X para Y. Esse significado é estendido metaforicamente, de um polo mais concreto para um polo mais abstrato, sucessivamente: primeiramente, a ação do sentido central passa a poder ser conceptualizada como causação também, e não apenas como ação física, ficando um pouco mais abstrata; depois, passa-se a poder conceptualizar a transferência apenas como causação de X para Y, estendendo o grau de abstração. Por fim, conceptualiza-se uma transferência ou direcionamento de experiência de X para Y, estendendo ainda mais o grau de abstração. Em outras palavras, os significados vão ficando cada vez mais abstratos/metafóricos, até chegarem a denotar uma experiência. Já os significados de [X GET $\left.{ }_{<M A N N E R>} \mathrm{Y}\right]$ e de [X $<$ RELATION> Y], para os quais não podemos postular uma relação de extensão metafórica, são tratados como adequações (ou "coersions", segundo Croft (1991)) ao padrão argumental transitivo.

Especificar uma rede de significados como essa é vantajoso para determinar relações de herança entre outras construções, por exemplo, a construção de sujeito agente-beneficiário (CIRÍACO, 2012), que herda a forma da construção transitiva e outros aspectos de sentido. Uma representação para a construção transitiva, em seu significado prototípico, seria como a que se segue: 
Figura 2 - Representação da construção

transitiva em seu significado prototípico

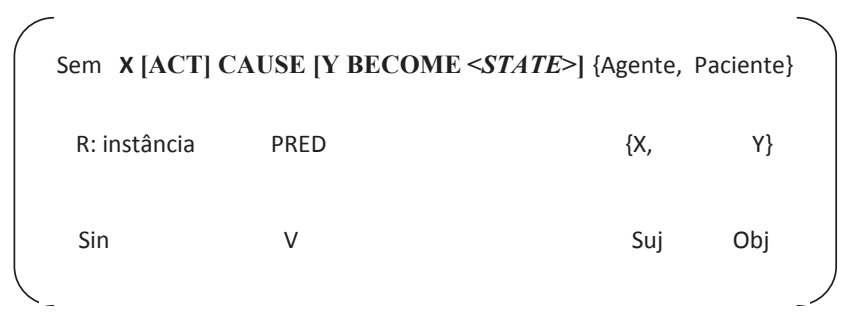

Fonte: Elaboração própria.

A figura 2 ilustra como ocorre a representação da construção transitiva em seu significado prototípico: o polo semântico traz a descrição do significado, dado em função dos predicados semânticos primitivos, o número e os papéis dos participantes envolvidos (agente e paciente). Observe que a qualidade semântica desses papéis é derivada do significado representado na construção. A relação (R) do predicado com a semântica da construção é de instância, ou seja, de elaboração: o predicado que se fundir com a construção deve elaborar o significado desta. No polo sintático, a construção mapeia X, o agente, na posição de sujeito, e Y, o paciente, na posição de objeto. Cada significado descrito para a construção transitiva corresponde a uma representação semelhante.

\section{Considerações finais}

Este artigo apresentou uma proposta de vinculação de uma teoria gramatical a uma metodologia semântico-lexical. A fim de descrever as construções de estrutura argumental na língua, dentro da perspectiva teórica da Gramática de Construções, mostramos que o uso da técnica de decompor o sentido dos verbos em predicados primitivos pode ser uma ferramenta útil na descrição do significado de dada construção em estudo. Para ilustrar a proposta, descrevemos seis grandes classes de verbos do português, mostrando, com exemplos, sua compatibilidade com a construção transitiva. A partir das representações semânticas dessas classes de verbos, analisamos o significado da construção transitiva, mostrando que sua semântica é ampla, e envolve diversos sentidos relacionados. Descrevemos seus significados em função de uma rede de sentidos, mostrando as relações entre eles. Posteriormente, ainda mostramos como o significado prototípico da construção transitiva, que é de uma transferência de ação de $\mathrm{X}$ para $\mathrm{Y}$, ou seja, [[X ACT] CAUSE [Y BECOME <STATE $]$ ], pode fazer parte da representação da construção. Por fim, realçamos que a pesquisa aqui descrita não tem a pretensão 
de ser exaustiva, mas parece se aplicar bem às classes analisadas, que, apesar de conterem ainda poucos verbos do português, se comparado ao total de verbos, são bem representativas da língua. Reconhecemos que a proposta aqui delineada trata-se de algo em desenvolvimento, sendo, portanto, uma versão preliminar das possíveis associações entre uma semântica lexical baseada em representações lexicais e a gramática de construções. Há ainda várias lacunas a serem abordadas em trabalhos futuros.

CIRÍACO, L. The transitive construction in Brazilian Portuguese: towards an association of Construction Grammar to Lexical Decomposition. Alfa, São Paulo, v.58, n.2, p.401-416, 2014.

- ABSTRACT: This paper aims to show how Construction Grammar Theory (GOLDBERG, 1995, 2006) may be associated with a lexical-semantic approach in order to observe verb classes, namely, the predicate decomposition of verbs. In other words, we assume that predicate decomposition can be a useful tool to describe the meaning of argument structure constructions. Therefore, we make an analysis of the transitive construction in Portuguese with the objective of illustrating our main proposal. Six major classes of verbs in BP are investigated, and their semantic representations are presented; then, they are checked with the transitive construction. The main goal is to reach the meaning of the construction, which, as shown before, may not be described in general terms, i.e. it cannot be given in terms of a schematic single meaning, but it actually can be considered in terms of a network of related meanings. Those meanings are understood as metaphorical extensions based on a prototypical meaning. At the end, we also provide a representation for the transitive construction in Portuguese taking into account its prototypical meaning.

- KEYWORDS: Transitive construction. Construction grammar. Predicate decomposition. Verb classes.

\section{REFERÊNCIAS}

CANÇADO, M. Verbal alternations in Brazilian Portuguese: a lexical semantic approach. Studies in Hispanic and Lusophone Linguistics, Blaine, v.3, n.1, p.77111, 2010.

CIRÍACO, L. A construção transitiva de sujeito agente-beneficiário. 2012. Manuscrito.

A hipótese do contínuo entre o léxico e a gramática e as construções incoativa, medial e passiva do PB. 2011. 225f. Tese (Doutorado em Estudos Linguísticos) - Faculdade de Letras, Universidade Federal de Minas Gerais, Belo Horizonte, 2011.

CIRÍACO, L.; CANÇADO, M. A alternância causativo-ergativa no português brasileiro. Matraga, Rio de Janeiro, v.16, n.24, p.216-231, 2009. 
CROFT,W. The structure of events and the structure of language. In:TOMASELLO, M. (Org.). The new psychology of language: cognitive and functional approaches to language structure. Mahwah: Lawrence Erlbaum Associates, 1998. p.67-92.

. Syntactic categories and grammatical relations: the cognitive organization of information. Chicago: University of Chicago Press, 1991.

CROFT,W.; CRUSE, D. A. Cognitive linguistics. Cambridge: Cambridge University Press, 2004.

FOLEY, W.; VAN VALIN, R. D. Functional syntax and universal grammar. Cambridge: Cambridge University Press, 1984.

GIVÓN, T. Syntax: a functional-typological introduction. Amsterdam: John Benjamins, 1984. v.1.

GOLDBERG, A. Constructions at work: the nature of generalization in language. Oxford: Oxford University Press, 2006.

Constructions: a construction grammar approach to argument structure. Chicago: University of Chicago Press, 1995.

JACKENDOFF, R. S. Semantic structures. Cambridge: MIT Press, 1990.

KEMMER, S. The middle voice. Amsterdam: John Benjamins Publishing Company, 1993.

LANGACKER, R. Cognitive grammar: a basic introduction. Oxford: Oxford University Press, 2008.

Foundations of cognitive grammar. Stanford: Stanford University Press, 1987. v.1.

LEVIN, B. English verb classes and alternations: a preliminary investigation. Chicago: University of Chicago Press, 1993.

LEVIN, B; ; RAPPAPORT-HOVAV, M. Reflections on manner/result complementarity. In: DORON, E.; RAPPAPORT-HOVAV, M.; SICHEL, I. (Org.). Syntax, lexical semantics, and event structure. Oxford: Oxford University Press, 2010. p.21-38.

Argument realization. Cambridge: Cambridge University Press, 2005.

Two structures for compositionally derived events. In: MATTHEWS, T.; STROLOVICH, D. (Org.). Semantics and linguistic theory (=SALT) IX. Ithaca: Cornell University, 1999. p.199-223.

. Building verb meanings. In: BUTT, M.; GEUDER,W. (Org.). The projection of arguments: lexical and compositional factors. Stanford: CSLI Publications, 1998. p.97-134. 
. Unaccusativity. at the syntax-lexical semantics interface. Cambridge: MIT Press, 1995.

Wiping the slate clean: a lexical semantic exploration. Cognition, Amsterdam, v.41, p.123-151, 1991.

PARSONS, T. Events in the Semantics of English: a study in subatomics semantics. Cambridge: MIT Press, 1990. (Currents Studies in Linguistic Series, n.19).

TALMY, L. Towards a cognitive semantics II: typology and process in concept structuring. Cambridge: MIT Press, 2000.

. Semantic causative types. In: SHIBATANI, M. (Org.). Syntax and semantics 6: the grammar of causative constructions. New York: Academic Press, 1976. p.43-116.

VAN VALIN, R. D. Exploring the syntax-semantics interface. Cambridge: Cambridge University Press, 2005.

VAN VALIN, R. D.; LAPOLLA, R. Syntax: structure, meaning and function. Cambridge: Cambridge University Press, 1997.

WUNDERLICH, D. Lexical decomposition. In: HINZEN,W. et al. (Org.). The Oxford handbook of compositionality. Oxford: Oxford University Press, 2009. p.1-18.

Predicate composition and argument extension as general options - a study in the interface of semantic and conceptual structure. In: STIEBELS, B.; WUNDERLICH, D. (Org.). The lexicon in focus. Berlin: Akademie Verlag, 2000. p.247-270.

Cause and the structure of verbs. Linguistic Inquiry, Cambridge, v.28, n.1, p.27-68, 1997.

Recebido em novembro de 2012.

Aprovado em abril de 2013. 